\title{
Optimization of Biological Synthesis of Silver Nanoparticles by Some Yeast Fungi
}

\author{
M.K. Zahran, A.A. Mohamed", F.M. Mohamed" ${ }^{* *}$ and M.H. \\ El-Rafie \\ Department of Chemistry, Faculty of Science, Helwan \\ University, ${ }^{*}$ Chemistry of Natural and Microbial Products \\ Department and ${ }^{* *}$ Textile Research Division, National \\ Research Center, Cairo, Egypt.
}

\begin{abstract}
$\Gamma$ HREE strains of yeast fungi namely Saccharomyces cerevisiae (Baker's yeast), Rhodotorula glutinis and Geotrichum candidum were tested for their potency in biosynthesis of AgNPs by direct exposure to silver nitrate solution. Absorption UV-Visible light spectroscopy is used to follow up with the reaction process. Transmission electron spectroscopy (TEM) is used to produce detailed information on the progress of reduction of silver nitrate (formation of silver nanoparticles) on the nanosecond timescale. Our measurements indicate that extracellular biosynthesis of silver nanoparticles AgNPs by different yeast strains produce AgNPs with the diameters in the range of $2.5-20 \mathrm{~nm}$. The three yeast strains are environmentally friendly microorganisms, and they are known for their formation of extracellular enzyme and metabolites in very large amounts, which could be utilized in AgNPs synthesis. The present work is undertaken with a view to accomplish controlled size and shape of AgNPs by making use of the yeasts to manipulate key parameters which control growth and other cellular activities.
\end{abstract}

Nanotechnology refers to the study of compounds of 100 nanometers or smaller in one dimension. Nanotechnology has a variety of applications in fields such as optics, electronics, bio-medicine, magnetics, mechanics, catalysis, energy science..., etc. Thus, developing different branches of nanotechnology confidently results in developing the related sciences, and is a consequential goal of scientific word ${ }^{(1-3)}$.

Metal nanoparticles are very fine and strong particles which have many applications in different fields like medical imaging (4) drug delivery ${ }^{(5)}$, electronics ${ }^{(6)}$, nanocomposites ${ }^{(7)}$, biolabeling ${ }^{(8,9)}$, biocide or antimicrobial agents ${ }^{(10)}$, filters ${ }^{(11)}$, sensors ${ }^{(12)}$ and non-linear optics ${ }^{(13)}$.

Progress in the field of nanotechnology has been rapid and with the development of innovative synthesis protocols and characterization techniques ${ }^{(14)}$. But most of the synthesis methods are limited to synthesis of nanoparticles in small quantities and poor morphology ${ }^{(15)}$. Chemical and physical synthesis methods often result in 
synthesis of a mixture of nanoparticles with poor morphology, and these methods also prove to be toxic to the environment due to the use of toxic chemicals and also of elevated temperatures for synthesis process ${ }^{(16,17)}$. There is an ever-growing need to develop clean, non-toxic, and environmentally friendly (green chemistry) synthetic procedures ${ }^{(18)}$. Biogenic synthesis of nanoparticles with controlled morphology needs more attention, as the biogenic synthesis of nanoparticles is carried out by using biological means like bacteria ${ }^{(19-21)}$, fungi ${ }^{(22-27)}$, actinomycetes ${ }^{(28,29)}$, lichens ${ }^{(30)}$, algae ${ }^{(31,32)} \ldots$, etc. The biogenic entities are found to secrete large amount of proteins which are found to be responsible for metal-ion reduction and morphology control ${ }^{(33)}$. The microbial cultures are easy to handle and also the downstream processing of biomass is simpler as compared to the synthetic methods ${ }^{(34)}$. Biogenic nanoparticles are toward a greener approach and environment friendly, as no toxic chemical is involved in synthesis, and also the synthesis process takes place at ambient temperature and pressure conditions ${ }^{(35,36)}$. Hence, a number of researchers are focusing toward the synthesis of biogenic nanoparticles compared with the chemically or physically synthesized nanoparticles ${ }^{(37-43)}$.

In the last decade, biosynthesis of metal nanoparticles is considered to be a new growing era to develop clean, nontoxic chemicals, environmentally benign solvents and renewable materials ${ }^{(44)}$. Inspiration from nature comes through yeast, fungi, bacteria and plant extracts for the control synthesis of biocompatible metal and semiconductor nanoparticles ${ }^{(45,46)}$.

Biological system has a unique ability to be self-organized and synthesizes molecules that have highly selective properties. These properties make them a prospective tool that can be used to synthesize nanodevices, and many biological systems are able to create an interface with the materials using them. From the process and application point of view it would be useful if the nanoparticles could be formed extracellularly.

As a part of our on-going investigation into the bio-synthesis of AgNPs using yeast secreted enzymes and proteins, an extensive screening study was carried out involving three yeast strains to identify a biological system for the extracellular biosynthesis of AgNPs. The present work is undertaken with a view to accomplish controlled size and shape of AgNPs by making use of the yeasts to manipulate key parameters which control growth and other cellular activities.

\section{Experimental}

\section{Materials for microbiological studies}

Test yeasts

The test yeasts used were kindly provided from The Regional Center for Mycology and Biotechnology, AL-Azhar University, Nasr City, Cairo.

The yeasts were maintained on Czapek Dox Agar (CDA)slants. 
Following is a list of the yeast strains those used through this work:

1- Saccharomyces cerevisiae (Baker's yeast).

2- Rhodotorula glutinis.

3- Geotrichum candidum.

Chemicals

Silver nitrate $\left(\mathrm{AgNO}_{3}\right)$, sodium nitrate $\left(\mathrm{NaNO}_{3}\right)$, magnesium sulfate penta hydrate $\left(\mathrm{MgSO}_{4} \cdot 5 \mathrm{H}_{2} \mathrm{O}\right)$, potassium chloride $(\mathrm{KCl})$, potassium dihhydrogen phosphate $\left(\mathrm{KH}_{2} \mathrm{PO}_{4}\right)$, ferrous sulfate $\left(\mathrm{FeSO}_{4}\right)$, sucrose and agar were all of laboratory grade chemicals.

\section{Culture media}

The following media were used throughout this work. All the ingredient was dissolved in $1000 \mathrm{ml}$ distilled water.

Czapek Dox Agar medium (CDA) (Maintenance medium): 2gm sodium nitrate, $0.5 \mathrm{gm}$ magnesium sulfate, $0.5 \mathrm{gm}$ potassium chloride, $1 \mathrm{gm}$ potassium dihydrogen phosphate, trace amount of ferrous sulfate, $20 \mathrm{gm}$ sucrose and $20 \mathrm{gm}$ agar were used as solidifying agent, the $\mathrm{pH}$ was adjusted at 6.5-7.They were used for maintenance of cultures. Stock cultures were maintained on CDA slants, kept in the refrigerator at $\left(5-6^{\circ} \mathrm{C}\right)$ and were subsequently re-cultured on the same medium each two weeks.

Fermentation media : The fermentation medium used in this research was Czapek Dox medium devoid of agar as a liquid medium. The $\mathrm{pH}$ of the overall medium components was adjusted to be 6.5-7. The ingredients of this medium were dissolved in fresh distilled water, and applied to $250 \mathrm{ml}$ Erlenmeyer conical flasks each containing $50 \mathrm{ml}$ of the medium was then sterilized at $121^{\circ} \mathrm{C}$ for $20 \mathrm{~min}$.

\section{Fermentation process}

Three yeast strains were used. Inoculation was done in two replicates by adding $1 \mathrm{ml}$ from 7 days old culture. Each yeast biomass was inoculated in two $250 \mathrm{ml}$ Erlenmeyer conical flasks containing $50 \mathrm{ml}$ of fermentation medium, and then incubated on a shaker incubator at $30 \pm 2{ }^{\circ} \mathrm{C}$ at $150 \mathrm{rpm}$. First and second samples were removed after 72 and $96 \mathrm{hr}$, respectively, for using in synthesis of silver nanoparticles.

For each sample, the contents of the fermentation medium were centrifuged and separated to two components by decantation-centrifugation. The first component was the biomass and the second was the medium filtrate. The $\mathrm{pH}$ of resultant filtrate was determined.

Preparation of silver nanoparticles

Three different tries were being done for the synthesis of silver nanoparticles. 
a. Preparation of silver nanoparticles using biomass.

b. Preparation of silver nanoparticles using biomass filtrate (supernatant).

c. Preparation of silver nanoparticles using biomass and the biomass removed from silver nanoparticles preparation reaction medium after $30 \mathrm{~min}$ from addition of $\mathrm{AgNO}_{3}$ to the reaction medium (the reaction preceded in the absence of biomass from the reaction medium).

Preparation of silver nanoparticles using biomass: Biomass was kept in silver nanoparticles preparation reaction medium tell the reduction done. Three yeast strains are used throughout this work:

1- Saccharomyces cerevisiae (Baker's yeast).

2- Rhodotorula glutinis.

3- Geotrichum candidum.

For each yeast strain inoculation was done in two replicates by adding $1 \mathrm{ml}$ from 7 days old culture. $1 \mathrm{ml}$ biomass was inoculated into three duplicate $250 \mathrm{ml}$ Erlenmeyer conical flasks containing $50 \mathrm{ml}$ of fermentation medium, and then incubated on a shaker incubator at $30 \pm 2{ }^{\circ} \mathrm{C}$ at $150 \mathrm{rpm}$. First, second and third samples were removed after 24,72 and $96 \mathrm{hr}$, respectively, for using in synthesis of silver nanoparticles.

For each sample, the biomass is recovered by decantation-centrifugation. Then the biomass washed extensively with fresh distilled water to remove any undesirable traces of the medium. The harvested biomass then re-suspended in $250 \mathrm{ml}$ Erlenmeyer conical flask containing $100 \mathrm{ml}$ fresh distilled water at $\mathrm{pH}$ 12. To this solution for each sample $\mathrm{AgNO}_{3}(0.1 \mathrm{~m} \mathrm{~mol})$ was added in the presence of cells. After $24 \mathrm{hr}$ the solution filtered (the filtration process was proceeded using filter paper Whitman No.1) to remove the cells and then subjected to U.V-Vis spectrophotometer.

Preparation of silver nanoparticles using biomass filtrate (supernatant):

The yeast cells from 72, $96 \mathrm{hr}$ incubation period for each yeast strain are recovered from each sample by decantation-centrifugation. Then the biomass washed extensively to remove undesirable traces of the medium. The washed biomass then re-suspended in $250 \mathrm{ml}$ Erlenmeyer conical flask containing $100 \mathrm{ml}$ fresh distilled water and the $\mathrm{pH}$ adjusted to $\mathrm{pH} 12$ and then kept in a shaker incubator at $30 \pm 2{ }^{\circ} \mathrm{C}$ at $150 \mathrm{rpm}$ for interval times $72,96 \mathrm{hr}$ and then each sample centrifuged to remove the biomass by decantation-centrifugation.

The filtrate (supernatant) prepared is being used in the synthesis of silver nanoparticles as the following:

(0.1 m mol) $\mathrm{AgNO}_{3}$ was added to the supernatant (biomass filtrate) and kept for $24 \mathrm{hr}$. After $24 \mathrm{hr}$ the samples for each strain show change in color and then subjected to U.V-Vis.

Egypt. J. Chem. 56, No. 1 (2013) 
Preparation of silver nanoparticles using biomass and the biomass removed from silver nanoparticles preparation reaction medium after 30 min from addition of $\mathrm{AgNO}_{3}$ to the reaction medium (the reaction preceded in the absence of biomass from the reaction medium)

For each yeast strain inoculation was done into two replicates by adding $1 \mathrm{ml}$ from 7 days old culture. $1 \mathrm{ml}$ biomass was inoculated into two duplicate $250 \mathrm{ml}$ Erlenmeyer conical flasks containing $50 \mathrm{ml}$ of fermentation medium, and then incubated on a shaker incubator at $30 \pm 2{ }^{\circ} \mathrm{C}$ at $150-200 \mathrm{rpm}$ for time intervals. First and second samples were removed after 72 and $96 \mathrm{hr}$, respectively, for using in synthesis of silver nanoparticles.

For each sample, the biomass is recovered by decantation-centrifugation. Then the biomass washed extensively with fresh distilled water to remove any undesirable traces of the medium. The harvested biomass then re-suspended in $250 \mathrm{ml}$ Erlenmeyer conical flask containing $100 \mathrm{ml}$ fresh distilled water at $\mathrm{pH}$ 12. To this solution for each sample $\mathrm{AgNO}_{3}(0.1 \mathrm{~m} \mathrm{~mol})$ was added in the presence of cells. After 30 min the solution filtered (the filtration process was proceeded using filter paper Whitman No.1) to remove the cells and then subjected to U.V-Vis spectrophotometer after $24 \mathrm{hr}$.

\section{Instruments for characterization}

The reduction of metal ions was routinely monitored by visual inspection of the solution, as well as, by UV-Visible light spectroscopy spectra and Transmission electron spectroscopy (TEM).

Ultra violet-visible (UV-Vis) spectra

Ultra violet-visible (UV-Vis) spectra has been proved to be quite sensitive to the formation of silver colloids because silver nanoparticles exhibit an intense absorption peak due to the surface plasmon excitation (it describes the collective excitation of condition electrons in a metal). Silver nanoparticles were recorded in. spectrophotometer from 300 to $700 \mathrm{~nm}$. The filtrate without adding silver nitrate was used as a blank.

Transmission Electron Microscope (TEM)

Particle size and shape were obtained with a JEOL-JEM-1200. Specimens for TEM measurements were prepared by dissolving a drop of colloid solution on a 400 mesh copper grid coated by an amorphous carbon film and evaporating the solvent in air at room temperature. The average diameter of the silver nanoparticles was determined from the diameter of 100 nanoparticles found in several arbitrarity chosen areas in enlarged microphotographs.

\section{Results and Discussion}

Preparation of silver nanoparticles using biomass

Study of the effect of $\mathrm{pH}$ on the process of the synthesis of silver nanoparticles

Figure 1 shows the effect of $\mathrm{pH}$ on stability of silver nanoparticles solution synthesized extracellularly by using the biomass of yeast strain Saccharomyces 
cerevisiae (Baker's yeast) presented in $100 \mathrm{ml}$ fresh distilled water. The $\mathrm{pH}$ of the biomass solution was adjusted to different values $8,10,11$ and 12 using diluted solutions of $\mathrm{NaOH}(0.1 \mathrm{~N})$. After that $0.1 \mathrm{~m}$ mole of $\mathrm{AgNO}_{3}$ was added to the biomass solution and vessels were kept under ambient conditions $\sim 25^{\circ} \mathrm{C}$ for $24 \mathrm{hr}$.

The results obtained from the figure indicate the following: (a) Increasing the $\mathrm{pH}$ of the biomass solution is accompanied by appreciable changes in the absorbance intensity, (b) the intensity of the absorbance bands increases by increasing the $\mathrm{pH}$ up to 12 , (c) the color and UV-Vis spectra indicate that there is no reaction before the $\mathrm{pH}$ range 10-12, increasing the $\mathrm{pH}$ up to 11 is accompanied by improvement in the extent of reduction with broaden plasmon peak and shifted to higher wavelength $c a 440 \mathrm{~nm}$, (d) when the $\mathrm{pH}$ of 12 is targeted the bands become stronger and symmetrical, with a pronounced bell shape at wavelength of $410 \mathrm{~nm}$, a band which could be assigned to the plasmon resonance of silver nanoparticles.

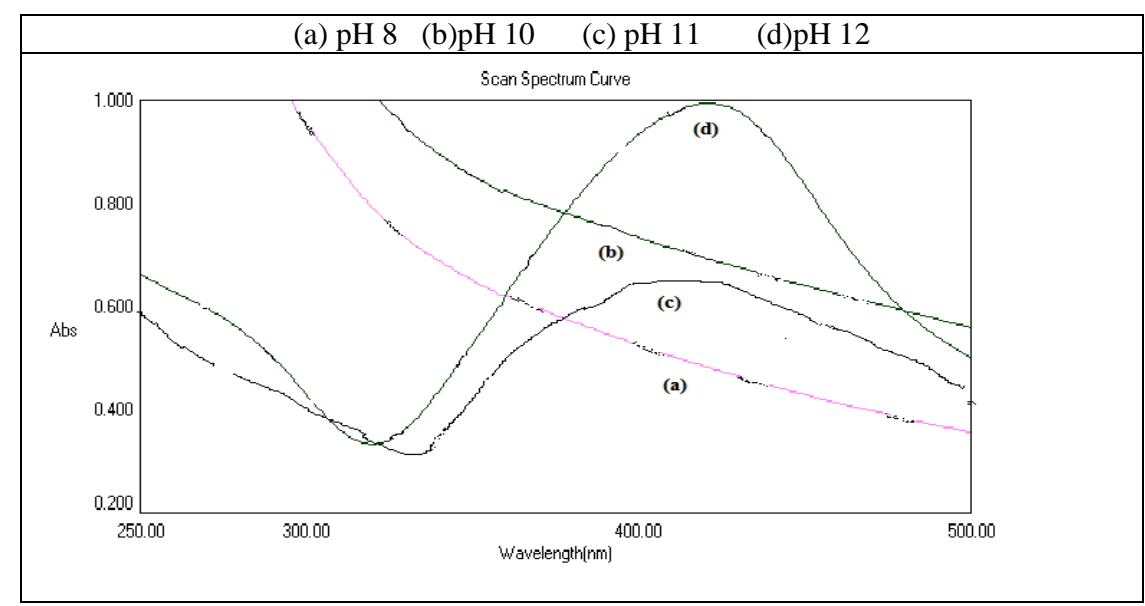

Reaction conditions: $100 \mathrm{ml}$ of biomass solution, $0.1 \mathrm{~m}$ mole $\mathrm{AgNO}_{3}$, Temperature $\sim 25^{\circ} \mathrm{C}$, Duration of $24 \mathrm{hr}$.

Fig.1. The UV-Vis spectra of silver nanoparticles prepared by Saccharomyces cerevisiae (Baker's yeast) at different $\mathrm{pHs}$.

Obviously, from the data showed in Fig.1 the extreme stability of the $\mathrm{Ag}^{\mathrm{o}}$ nanoparticles is attained at higher $\mathrm{pH}(11-12)$ but at lower $\mathrm{pH}(8-10)$, the broading of the absorbance with red shift of absorbance maxima is observed indicating the aggregation of particles. This could be attributed to the capping proteins secreted by the yeast strain Saccharomyces cerevisiae. The so secreted proteins are sufficient enough for the formation of silver nanoparticles at higher $\mathrm{pH}$. At lower $\mathrm{pH}$ on the other hand, the protein structure gets affected and the protein gets denatured and loses its activity.

Egypt. J. Chem. 56, No. 1 (2013) 
Based on the above, it can be concluded that the proteins secreted by the yeast Saccharomyces cerevisiae, in solution for capping of silver nanoparticles are stable in alkaline $\mathrm{pH}$ but not in acidic $\mathrm{pH}$. This depicts the efficiency of the secreted proteins and enzymes as stabilizing and reducing agents in alkaline medium.

Study of the effect of the three different yeast strains incubation period on the synthesis of silver nanoparticles

For each yeast strain the effect of the incubation period was studied by the variation in the incubation period intervals $24,48,72$ and $96 \mathrm{hr}$.

Figure 2 represents the U.V-Vis spectra for the AgNps solution prepared using the yeast strain Saccharomyces cerevisiae (Baker's yeast), Geotrichum candidum and Rhodotorula glutinis by the variation in the incubation time 24, 48, 72 and $96 \mathrm{hr}$.

From Fig.2, it is obvious that the best results obtained for the silver nanoparticles synthesis is $72 \mathrm{hr}$ incubation period for the three strains.

Preparation of AgNPs by the use of biomass has a real defect as the formed AgNPs attached to the cell wall of biomass which decrease the resultant AgNPs solution concentration. In order to avoid this lack in yield biomass filtrate (supernatant) will be used in AgNPs synthesis.

Preparation of silver nanoparticles using biomass filtrate (supernatant) For yeast strain Saccharomyces cerevisiae (Baker's yeast)

Figure $3 \mathrm{a}$ represents the UV-Vis spectra of silver nanoparticles prepared using yeast strain Saccharomyces cerevisiae for incubation period $72 \mathrm{hr}$ and the biomass re-suspended for $96 \mathrm{hr}$ in $100 \mathrm{ml}$ distilled water. Then biomass removed by decantation-centrifugation. After that $0.1 \mathrm{~m}$ mole $\mathrm{AgNO}_{3}$ is added to the prepared filtrate (supernatant), temperature $\sim 25^{\circ} \mathrm{C}$, Duration of $24 \mathrm{hr}$. After $72 \mathrm{hr}$ from addition of $(0.1 \mathrm{~m} \mathrm{~mol}) \mathrm{AgNO}_{3}$, the same solution re-subjected to U.V-Vis spectroscopy (Fig.3b) which shows that the solution of silver nanoparticles formed by this condition is not stable. Coagulation occurred to the formed nanoparticles by time. This indicates that there is lack in the capping protein.

Figure 4a represents The UV-Vis spectra of silver nanoparticles prepared using yeast strain Saccharomyces cerevisiae for incubation period $96 \mathrm{hr}$ and the biomass re-suspended for $72 \mathrm{hr}$ in $100 \mathrm{ml}$ distilled water. Then biomass removed by decantation-centrifugation. After that $0.1 \mathrm{~m}$ mole $\mathrm{AgNO}_{3}$ is added to the prepared filtrate (supernatant), temperature $\sim 25^{\circ} \mathrm{C}$, duration of $24 \mathrm{hr}$. After $72 \mathrm{hr}$ from addition of $(0.1 \mathrm{~m} \mathrm{~mol}) \mathrm{AgNO}_{3}$ the same solution re-subjected to U.V-Vis spectroscopy (Fig.4b).

Figure 4 shows that the formed solution still stable by time and there is no change in the U.V-Vis spectra results. 

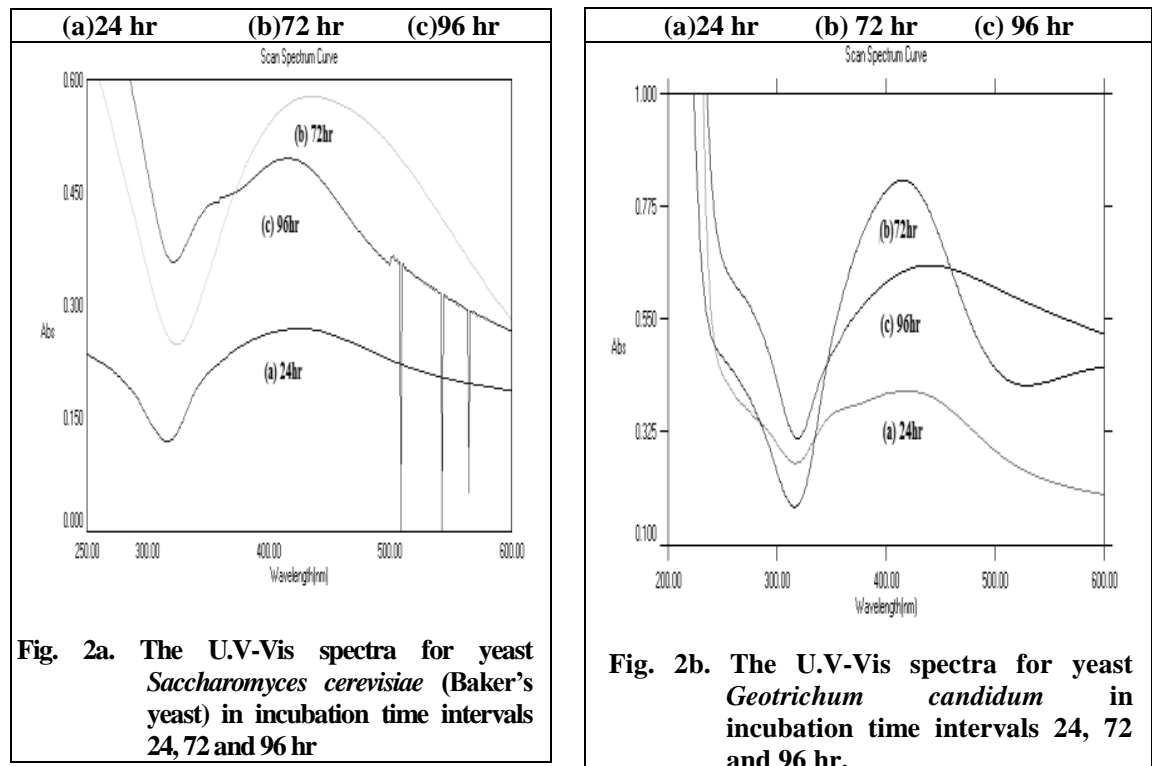

Fig. 2b. The U.V-Vis spectra for yeast Geotrichum candidum in incubation time intervals 24,72 and $96 \mathrm{hr}$.

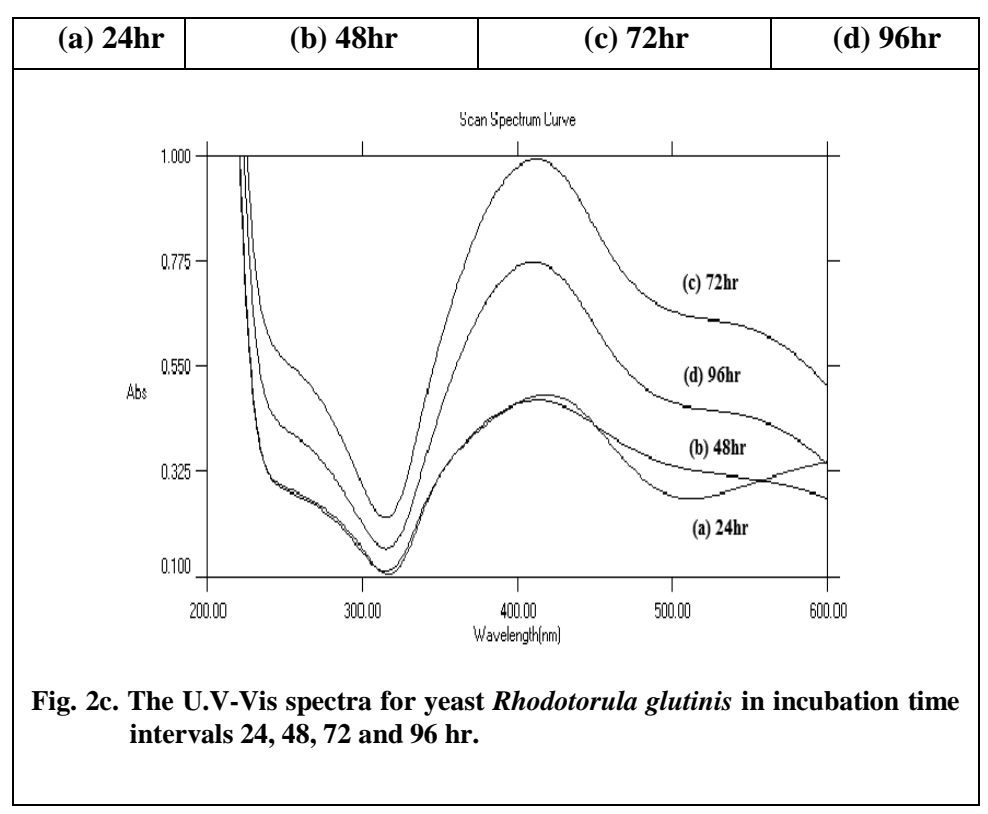

Fig. 2. Study of the effect of the three different yeast strains incubation period on the synthesis of silver nanoparticles. 


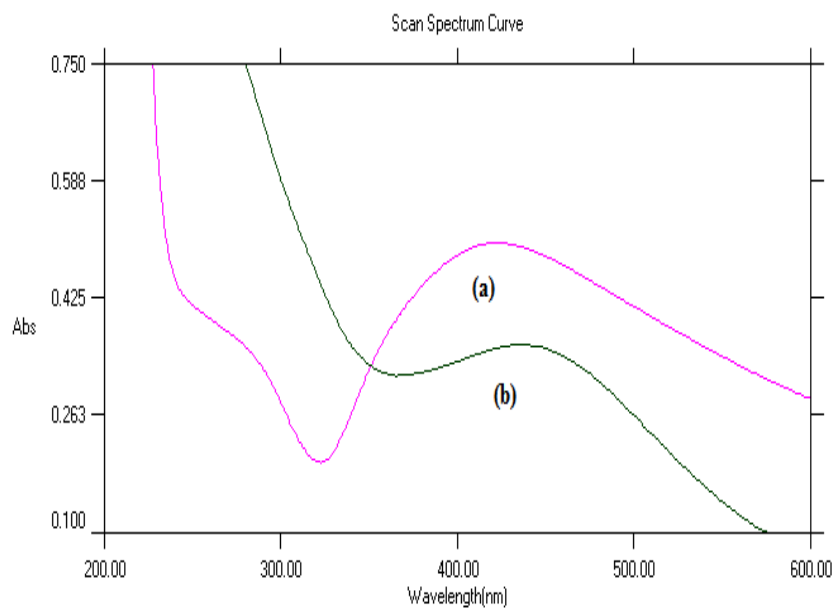

Reaction conditions: $0.1 \mathrm{~m}$ mole $\mathrm{AgNO}_{3}$, Temperature $25^{\circ} \mathrm{C}, \mathrm{pH} 12$.

Fig.3 The UV-Vis spectra recorded as a function of time; for the biomass filtrate of yeast Saccharomyces cerevisiae for incubation period $72 \mathrm{hr}$ and the biomass re-suspended for $96 \mathrm{hr}$.

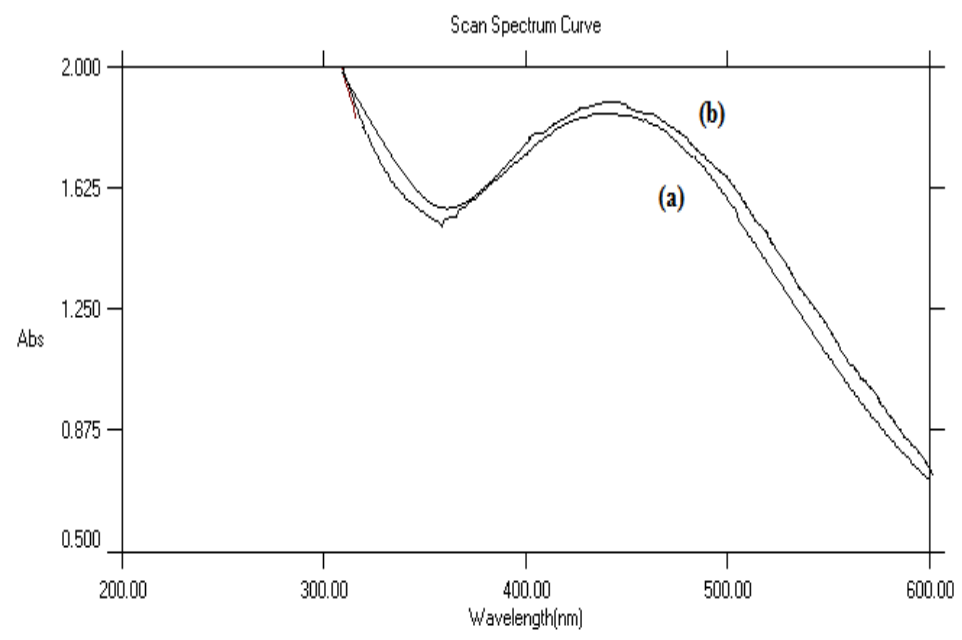

Reaction conditions: $0.1 \mathrm{~m}$ mole $\mathrm{AgNO}_{3}$, Temperature $25^{\circ} \mathrm{C}, \mathrm{pH} 12$.

Fig. 4. The UV-Vis spectra recorded as a function of time; for the biomass filtrate of yeast Saccharomyces cerevisiae for incubation period $96 \mathrm{hr}$ and the biomass re-suspended for $72 \mathrm{hr}$. 
From Fig.3 and 4 for the yeast strain Saccharomyces cerevisiae in the formation of silver nanoparticles $\mathrm{AgNps}$ by using biomass supernatant (in the absence of biomass from the reaction medium) the best results obtained for incubation period $96 \mathrm{hr}$ and the biomass harvested and re-suspended for $72 \mathrm{hr}$ in $100 \mathrm{ml}$ distilled water at $\mathrm{pH} 12$ then $(0.1 \mathrm{~m} \mathrm{~mol}) \mathrm{AgNO}_{3}$ added.

\section{For yeast strain Geotrichum candidum}

Figure 5a represent the UV-Vis spectra of silver nanoparticles prepared using yeast strain Geotrichum candidum for incubation period $72 \mathrm{hr}$ and the biomass re-suspended for $96 \mathrm{hr}$ in $100 \mathrm{ml}$ distilled water. Then biomass removed by decantation-centrifugation. After that $0.1 \mathrm{~m} \mathrm{~mole} \mathrm{AgNO}_{3}$ is added to the prepared filtrate (supernatant), Temperature $25^{\circ} \mathrm{C}$, Duration of $24 \mathrm{hr}$. After $72 \mathrm{hr}$ from addition of $(0.1 \mathrm{~m} \mathrm{~mol}) \mathrm{AgNO}_{3}$, the same solution re-subjected to U.V-Vis spectroscopy. The following (Fig. 5) shows shifting of the peak to higher wavelength from $441(\mathrm{~nm})$ to $466(\mathrm{~nm})$ from that in Fig.5b. The solution of silver nanoparticles formed by this condition is not stable as coagulation occurred to the formed nanoparticles by time.

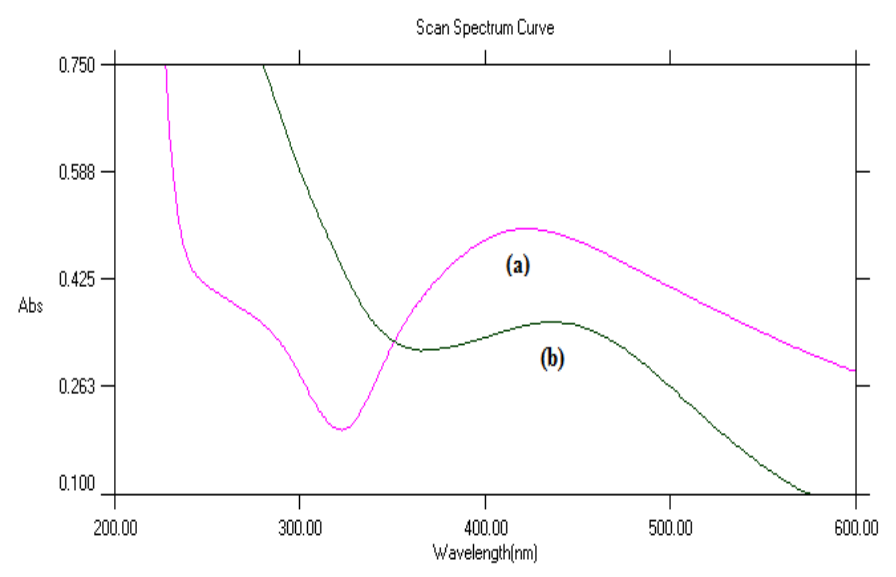

Reaction conditions: $0.1 \mathrm{~m}$ mole $\mathrm{AgNO}_{3}$, Temperature $25^{\circ} \mathrm{C}, \mathrm{pH} 12$.

Fig. 5. The UV-Vis spectra recorded as a function of time; for the biomass filtrate of yeast Geotrichum candidum for incubation period $72 \mathrm{hr}$ and the biomass resuspended for $96 \mathrm{hr}$.

Figure $6 a$ represents the UV-Vis spectra of silver nanoparticles prepared using yeast strain Geotrichum candidum for incubation period $96 \mathrm{hr}$ and the biomass re-suspended for $72 \mathrm{hr}$ in $100 \mathrm{ml}$ distilled water. Then biomass removed by decantation-centrifugation. After that $0.1 \mathrm{~m}$ mole AgNO3 is added to the prepared filtrate (supernatant), Temperature $25^{\circ} \mathrm{C}$, Duration of $24 \mathrm{hr}$. After $72 \mathrm{hr}$ from addition of $(0.1 \mathrm{~m} \mathrm{~mol}) \mathrm{AgNO}$, the same solution re-subjected 
to U.V-Vis spectroscopy (Fig.6b). Figure 6 shows that in this condition the reaction (reduction of $\mathrm{Ag}+$ to $\mathrm{AgNps}$ ) needs more time to be done.

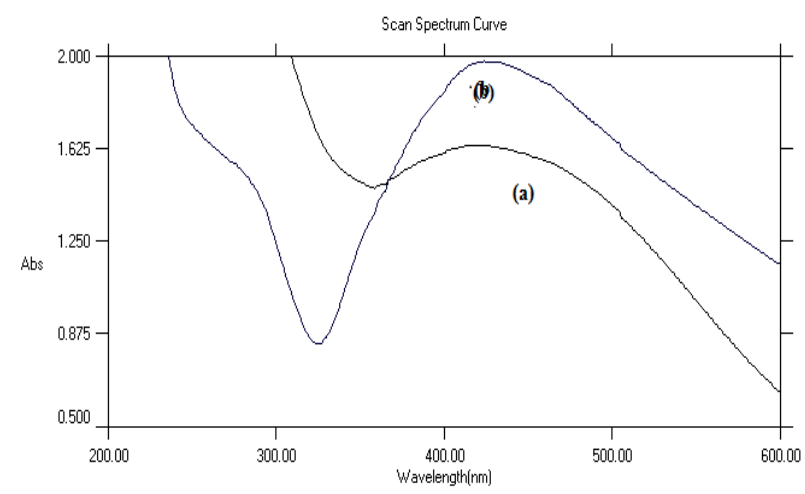

Reaction conditions: $0.1 \mathrm{~m}$ mole $\mathrm{AgNO}_{3}$, Temperature $25^{\circ} \mathrm{C}, \mathrm{pH} 12$.

Fig. 6. The UV-Vis spectra recorded as a function of time; for the biomass filtrate of yeast Geotrichum candidum for incubation period $96 \mathrm{hr}$ and the biomass resuspended for $72 \mathrm{hr}$.

For yeast strain Rhodotorula glutinis

Figure7a represents the UV-Vis spectra of silver nanoparticles prepared using yeast strain Rhodotorula glutinis for incubation period $72 \mathrm{hr}$ and the biomass re-suspended for $96 \mathrm{hr}$ in $100 \mathrm{ml}$ distilled water. Then biomass removed by decantation-centrifugation. After that $0.1 \mathrm{~m}$ mole $\mathrm{AgNO}_{3}$ is added to the prepared filtrate (supernatant), temperature $\sim 25^{\circ} \mathrm{C}$, Duration of $24 \mathrm{hr}$. After $72 \mathrm{hr}$ from addition of $(0.1 \mathrm{~m} \mathrm{~mol}) \mathrm{AgNO}_{3}$, the same solution re-subjected to U.V-Vis spectroscopy (Fig. 7b). Figure7 shows that in this condition the reaction (reduction of $\mathrm{Ag}^{+}$to $\mathrm{AgNps}$ ) needs more time to be done.

Figure 8a represents the UV-Vis spectra of silver nanoparticles prepared using yeast strain Rhodotorula glutinis for incubation period $96 \mathrm{hr}$ and the biomass re-suspended for $72 \mathrm{hr}$ in $100 \mathrm{ml}$ distilled water. Then biomass removed by decantation-centrifugation. After that $0.1 \mathrm{~m}$ mole $\mathrm{AgNO}_{3}$ is added to the prepared filtrate (supernatant), Temperature $\sim 25^{\circ} \mathrm{C}$, Duration of $24 \mathrm{hr}$. After $72 \mathrm{hr}$ from addition of $(0.1 \mathrm{~m} \mathrm{~mol}) \mathrm{AgNO}_{3}$ the same sample re-subjected to U.V-Vis (Fig.8b). From the data showed in Fig. 8 it is clear that there is no change in the solution by time (solution is stable by time).

Preparation of AgNPs by biomass filtrate (supernatant) is very sophisticated as it needs much more time and several processing steps besides the obtained yield is less than that obtained by the use of biomass . 


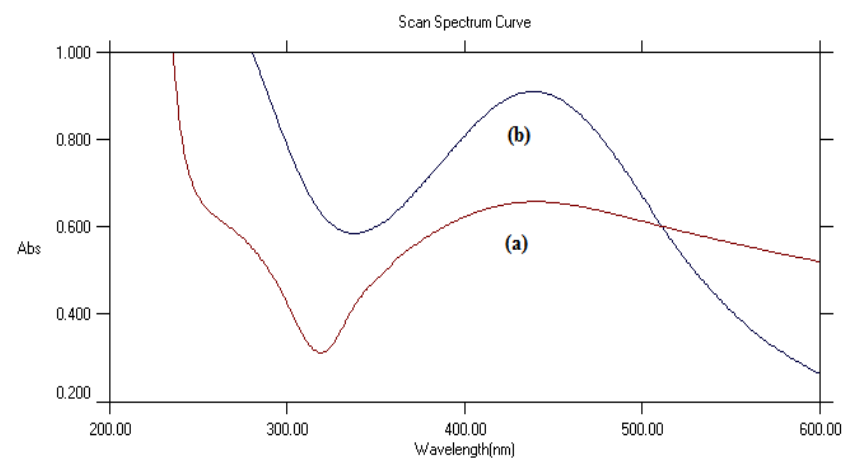

Reaction conditions: 0.1m mole $\mathrm{AgNO}_{3}$, Temperature $25^{\circ} \mathrm{C}, \mathrm{pH} 12$.

Fig. 7. The UV-Vis spectra recorded as a function of time; for the biomass filtrate of yeast Rhodotorula glutinis for incubation period $72 \mathrm{hr}$ and the biomass resuspended for $96 \mathrm{hr}$.

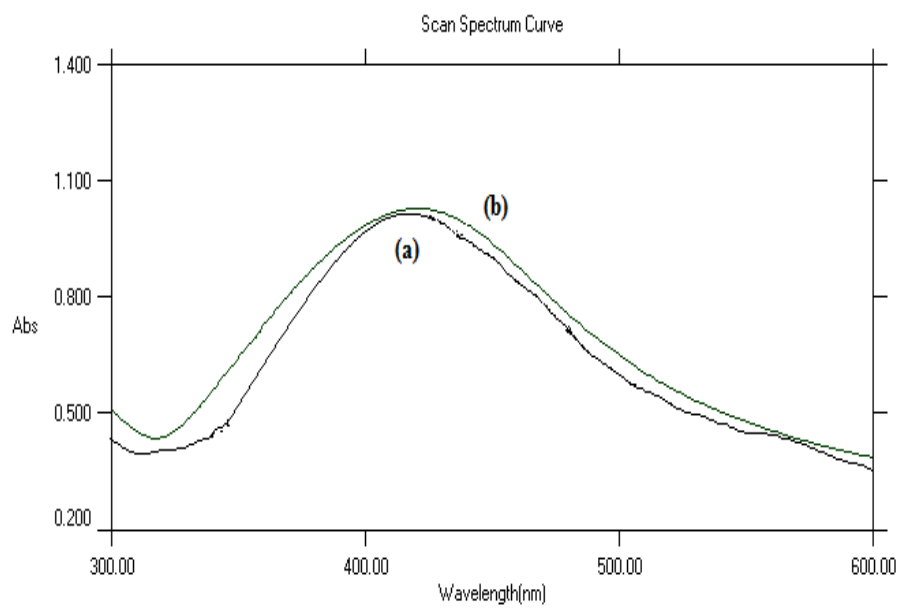

Reaction conditions: $0.1 \mathrm{~m}$ mole $\mathrm{AgNO}_{3}$, Temperature $25^{\circ} \mathrm{C}, \mathrm{pH} 12$.

Fig. 8. The UV-Vis spectra recorded as a function of time; for the biomass filtrate of yeast Rhodotorula glutinis for incubation period $96 \mathrm{hr}$ and the biomass resuspended for $72 \mathrm{hr}$.

Preparation of silver nanoparticles using biomass and the biomass removed from silver nanoparticles reaction medium after 30 min from addition of $\mathrm{AgNO}_{3}$ to the reaction medium (the reaction preceded in the absence of biomass from the reaction medium

Figure 9a-c represents The U.V-Vis spectra for yeast Saccharomyces cerevisiae (Baker's yeast), Geotrichum candidum and Rhodotorula glutinis, respectively after incubation period $72 \mathrm{hr}$ and the cells removed from the reaction medium after $30 \mathrm{~min}$ from the addition of $(0.1 \mathrm{~m} \mathrm{~mol})$ AgNO3.

Egypt. J. Chem. 56, No. 1 (2013) 

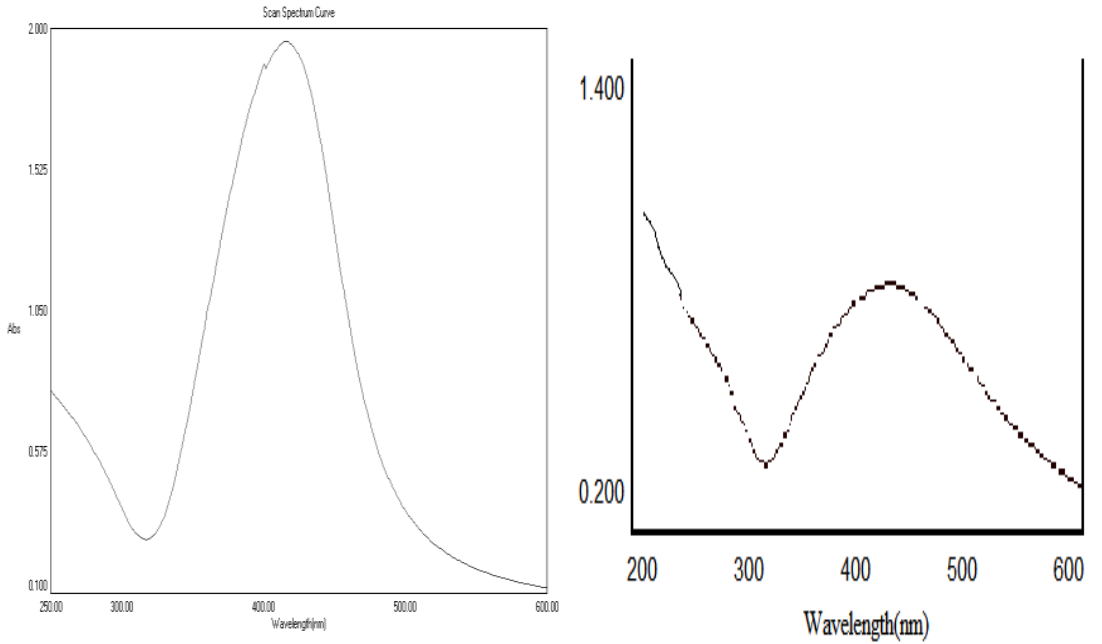

Fig.9a. The U.V-Vis spectra for yeast Saccharomyces cerevisiae (Baker's yeast) in incubation time in $72 \mathrm{hr}$ and the cells removed from the reaction medium after $30 \mathrm{~min}$ from the addition of AgNO3.

Fig.9b. The U.V-Vis spectra for yeast Geotrichum candidum in incubation time $72 \mathrm{hr}$ and the cells removed from the reaction medium after 30min from the addition of AgNO3.

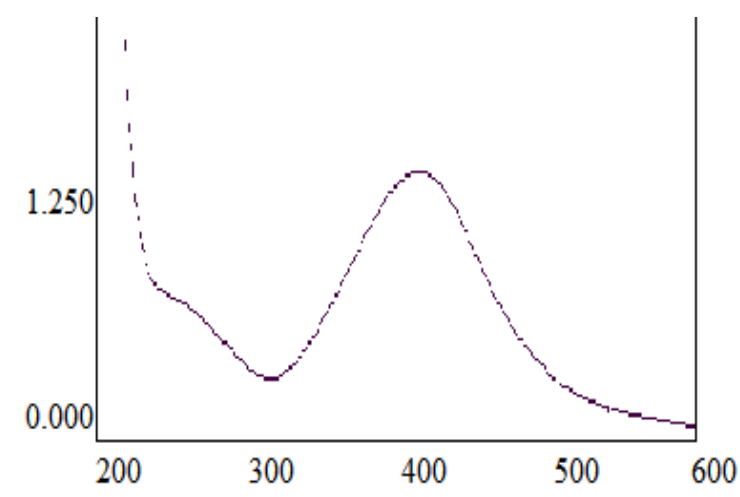

Fig. 9c. The U.V-Vis spectra for yeast Rhodotorula glutinis in incubation time $72 \mathrm{hr}$ and the cells removed from the reaction medium after 30min from the addition of AgNO3.

Fig.9. U.V-Vis spectra of AgNPs solution prepared by the third technique for the three yeast strains. 
Figure 10a and $\mathrm{b}$ show the TEM micrograph and the particle size and particle size distribution, respectively, using $1 \mathrm{ml}$ from 7 days old culture of yeast strain Saccharomyces cerevisiae (Baker's yeast), incubation period was 72 $\mathrm{hr}$, addition of $\mathrm{AgNO}_{3}$ done in the presence of cells. Biomass removed before the reaction done (after $30 \mathrm{~min}$ ).

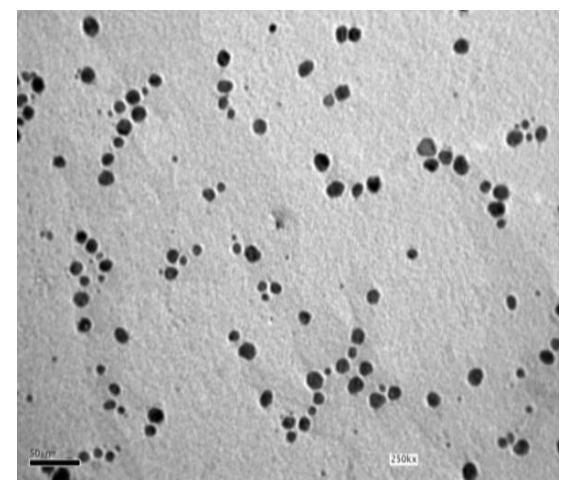

Fig.10a. TEM image of silver nanoparticles formed using $1 \mathrm{ml}$ from 7 days old culture of yeast strain Saccharomyces cerevisiae (Baker's yeast), incubation period was 72 $\mathrm{hr}$, addition of $\mathrm{AgNO}_{3}$ done in the presence of cells. Biomass removed before the reaction done (after 30 min).

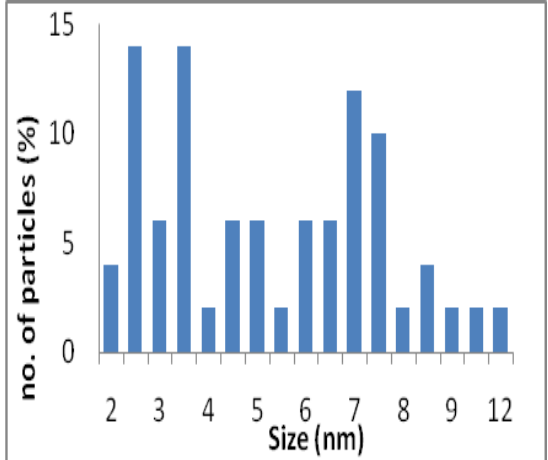

Fig.10b. Histogram showing the particle size and particle size distribution of silver nanoparticles prepared using $1 \mathrm{ml}$ mole silver nitrate in $1 \mathrm{ml}$ biomass of yeast strain Saccharomyces cerevisiae (Baker's yeast) suspended in $100 \mathrm{ml}$ fresh distilled water.

Fig.10 (a) TEM picture, (b) the histogram of AgNPs prepared by the third technique for yeast strain Saccharomyces cerevisiae (Baker's yeast).

Figure 11a and $\mathrm{b}$ show the TEM micrograph and particle size distribution, respectively, using $1 \mathrm{ml}$ from 7 days old culture of yeast strain Geotrichum candidum, incubation period was $72 \mathrm{hr}$, addition of $\mathrm{AgNO}_{3}$ done in the presence of cells. Biomass removed before the reaction done (after $30 \mathrm{~min}$ ).

Figure $12 \mathrm{a}$ and $\mathrm{b}$ show the TEM micrograph and particle size distribution, respectively, using $1 \mathrm{ml}$ from 7 days old culture of yeast strain Rhodotorula glutinis, incubation period was $72 \mathrm{hr}$, addition of $\mathrm{AgNO}_{3}$ done in the presence of cells. Biomass removed before the reaction done (after $30 \mathrm{~min}$ ).

Synthesis of AgNPs using these three yeast strains (Saccharomyces cerevisiae, Geotrichum candidum and Rhodotorula glutinis) by this technique is much promising as it gives high yield of AgNPs concentration, is very easy to handle, does not need long time and gives small AgNPs size range (1.5-20nm). 


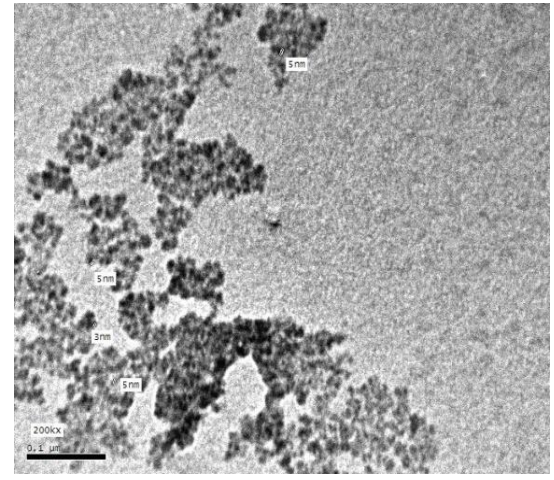

Fig. 11a. TEM image of silver nanoparticles formed using $1 \mathrm{ml}$ from 7 days old culture of yeast strain Geotrichum candidum, incubation period was 72 $\mathrm{hr}$, addition of $\mathrm{AgNO}_{3}$ done in the presence of cells. Biomass removed before the reaction done (after 30 min).

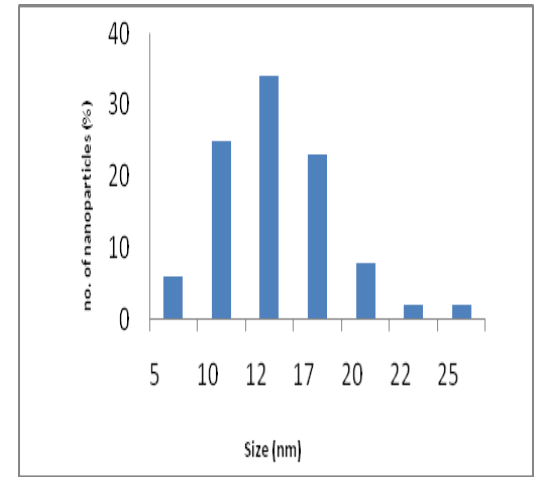

Fig. 11b. Histogram showing the particle size and particle size distribution of silver nanoparticles prepared using $1 \mathrm{ml}$ mole silver nitrate in $1 \mathrm{ml}$ biomass of yeast strain Geotrichum candidum suspended in $100 \mathrm{ml}$ fresh distilled water.

Fig.11. (a) TEM picture, (b) the histogram of AgNPs prepared by the third technique for yeast strain Geotrichum candidum.
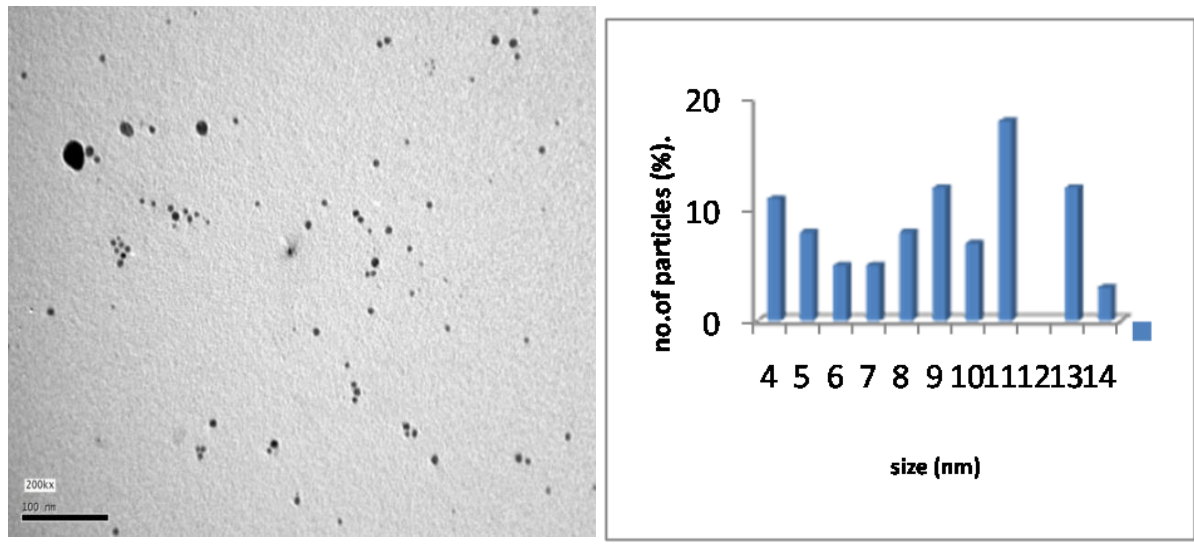

Fig. 12a. TEM image of silver nanoparticles formed using $1 \mathrm{ml}$ from 7 days old

Fig. 12b. Histogram showing the particle size culture of yeast strain Rhodotorula glutinis, incubation period was $72 \mathrm{hr}$, addition of $\mathrm{AgNO}_{3}$ done in the presence of cells. Biomass removed before the reaction done (after $30 \mathrm{~min}$ ). and particle size distribution of silver nanoparticles prepared using $1 \mathrm{ml}$ mole silver nitrate in $1 \mathrm{ml}$ biomass of yeast strain Rhodotorula glutinis suspended in $100 \mathrm{ml}$ fresh distilled water

Fig.12.(a) TEM picture, (b) the histogram of AgNPs prepared by the third technique for yeast strain Rhodotorula glutinis. 


\section{Conclusion}

In comparison, the preparation of AgNPs by the use of biomass has a real defect as the formed AgNPs attached to the cell wall of biomass which decreases the resultant AgNPs solution concentration, preparation of AgNPs by biomass filtrate (supernatant) is very sophisticated as it needs much more time and several processing steps beside the obtained yield is less than that obtained by the use of biomass.

For the previous reasons the third technique was applied to avoid both the lack in the resultant yield and longer time and several steps.

The results from the third technique indicated that it is the best way for the preparation of AgNPs by the used three yeast strains as it gives high yield of AgNPs concentration, is very easy to handle, does not need long time and gives small AgNPs size range (1.5-20nm).

From our investigations, the three yeast strains are promising in the biosynthesis of AgNPs, from TEM micrograph, the particle size and particle size distribution results, we found that the yeast strain a Saccharomyces cerevisiae (Baker's yeast) is the best candidate.

\section{References}

1. Moghaddam, K.M., An introduction to microbial metal nanoparticle preparation method. Journal of Young Investigators. (January 2010).

2. Mohanpuria, P., Biosynthesis of nanoparticles: technological concepts and future applications. Journal of Nanoparticle Research. 10(3), 507-517 (2008).

3. Bhattacharya, D. and Gupta, R.K., Nanotechnology and potential of microorganisms. Crit Rev Biotechnol. 24(4),199-204(2005).

4. Lee, H.Y., PET/MRI dual-modality tumor imaging using arginine-glycine-aspartic (RGD)-conjugated radiolabeled iron oxide nanoparticles. Journal of Nuclear Medicine. 49(8), 1371-1379. (2008).

5. Horcajada, P., Flexible porous metal-organic frameworks for a controlled drug delivery. Journal-American Chemical Society, 130(21), 6774-6780 (2008).

6. Lipovskii, A.A., Electric field imprinting of sub-micron patterns in glass-metal nanocomposites. Nanotechnology, 19, 415304-415309 (2008).

7. Ting, P.K., Synthesis and characterization of silica-titania nanocomposite via a combination of sol-gel and mechanochemical process. Journal of Alloys and Compounds, 446(1-2), 304-307 (2007).

Egypt. J. Chem. 56, No. 1 (2013) 
8. Tan, M., Synthesis and characterization of titania-based monodisperse fluorescent europium nanoparticles for biolabeling. Journal of Luminescence, 117(1), 20-28 (2006).

9. Parak, W.J., Labelling of cells with quantum dots. Nanotechnology, 16, R9-R25 (2005).

10. Kirchner, C., Cytotoxicity of colloidal CdSe and CdSe/ZnS nanoparticles. Nano Letters, 5(2), 331-338 (2004).

11. Boskovic, L., Filter efficiency as a function of nanoparticle velocity and shape. Journal of Aerosol Science, 39(7), 635-644 (2008).

12. Jiang, K., Manipulation of $\mathrm{ZnO}$ nanostructures using dielectrophoretic effect. Sensors and Actuators B: Chemical. 134(1), 79-88 (2008).

13. Ebothe, J., Pd nanoparticles as new materials for acoustically induced non-linear optics. Physica E: Low-dimensional Systems and Nanostructures, 35(1), 121-125 (2006).

14. Sharma, V.K., Yngard, R.A. and Linm Y.A., Silver nanoparticles: green synthesis and their antimicrobial activities. $d v$ Colloid Interface Sci. 145, 83-96(2009).

15. Sau, T.K. and Rogach, A.L., Nonspherical noble metal nanoparticles: colloidchemical synthesis and morphology control. Adv Mater. 22(16), 1781-1804(2010).

16. Rai, M., Yadav, A. and Gade, A., Current trends in phytosynthesis of metal nanoparticles. Crit. Rev. Biotechnol. 28(4), 277-284(2008).

17. Birla, S.S., Tiwari, V.V., Gade, A.K., Ingle, A.P., Yadav, A.P. and Rai, M.K., Fabrication of silver nanoparticles by Phoma glomerata and its combined effect against Escherichia coli, Pseudomonas aeruginosa and Staphylococcus aureus. Lett. Appl. Microbiol. 48,173-179(2009).

18. El-Rafie, M.H., EL-Naggar, M. H., Ramadan, M. E., Fouda, M.A., AL-Dyab, M. M. G. and Hebeish, A., Environmental synthesis of silver nanoparticles using hydroxypropyle starch and their characterization. Carbohydrate polymer, 86, 630-635 (2011).

19. Husseiny, M.I., El-Aziz, M.A., Badr, Y. and Mahmoud, M.A., Biosynthesis of gold nanoparticles using Pseudomonas aeruginosa Spectrochim Acta A. Mol Biomol. Spectrosc. 67,1003-1006(2007).

20. Shahverdi, A.R., Minaeian, S., Shahverdi, H.R., Jamalifar, H. and Nohi, A.A., Rapid synthesis of silver nanoparticles using culture supernatants of enterobacteria: a novel biological approach. Process Biochem. 42,919-923(2007).

21. Shahverdi, N., Wong, C.W. and Nur Yasumira, A.A., Rapid biosynthesis of silver nanoparticles using culture supernatant of bacteria with microwave irradiation. Eur. J. Chem. 6(1),61-70(2009) 
22. El-Rafie, M.H., Mohamed, A.A., Shaheen, Th.I. and Hebeish, A., Antimicrobial effect of silver nanoparticles produced by fungal process on cotton fabrics. Carbohydrate Polymers, 80, 779-782 (2010).

23. Kumar, A.S., Ansary, A.A., Ahmad, A. and Khan, M.I., Extracellular biosynthesis of CdSe quantum dots by the fungus, Fusarium oxysporum. J. Biomed. Nanotechnol. 3,190-194 (2007a).

24. Kumar, S.A., Abyaneh, M.K., Gosavi,S.W., Kulkarni, S.K., Pasricha, R., Ahmad, A. and Khan,M.I., Nitrate reductase-mediated synthesis of silver nanoparticles from AgNO3 . Biotechnol Lett. 29,439-445 (2007b).

25. Parikh, R.Y., Singh, S., Prasad, B.L.V., Patole M.S., Sastry, M. and Shouche, Y.S., Extracellular synthesis of crystalline silver nanoparticles and molecular evidence of silver resistance from Morganella sp: towards understanding biochemical synthesis mechanism. Chem. Bio. Chem. 9, 1415-1422(2008).

26. Gajbhiye, M., Kesharwani, J., Ingle, A., Gade, A. and Rai, M., Fungus-mediated synthesis of silver nanoparticles and their activity against pathogenic fungi in combination with fluconazole. Nanomed. Anotechnol. Biol. Med. 5, 382-386 (2009).

27. Govender, Y., Riddin, T., Gericke, M. and Whiteley, C.G., Bioreduction of platinum salts into nanoparticles: a mechanistic perspective. Biotechnol. Lett. 31, 95-100 (2009).

28. Ahmad, A., Mukherjee, P., Senapati, S., Mandal, D., Khan, M.I., Kumar, R. and Sastry, M., Extracellular biosynthesis of silver nanoparticles using the fungus Fusarium oxysporum. Colloids Surf. B. 28,313-318 (2003a).

29. Ahmad, A., Senapati, S., Khan, M.I., Kumar, R., Ramani, R., Shrinivas, V. and Sastry, M., Intracellular synthesis of gold nanoparticles by a novel alkalotolerant actinomycete, Rhodococcus species. Nanotechnology, 14, 824-828 (2003b).

30. Shahi, S.K. and Patra, M., Microbially synthesized bioactive nanoparticles and their formulation active against human pathogenic fungi. Rev. Adv. Mater. Sci. 5, 501-509(2003).

31. Singaravelu, G., Arockiamary, J.S., Ganesh, Kumar, V. and Govindraju, K., A novel extracellular synthesis of monodisperse gold nanoparticles using marine alga, Sargassum wightii Greville. Colloid Surf. B: Biointerface, 57, 97-101 (2007).

32. Chakraborty, N., Banerjee, A., Lahiri, S., Panda, A., Ghosh, A.N. and Pal, R. J., Biorecovery of gold using cyanobacteria and eukaryotic alga with special reference to nanogold formation - a novel phenomenon. Appl. Phycol. 21(1), 145-152(2009).

33. Thakkar, K.N., Mhatre, S.S. and Parikh, R.Y., Biological synthesis of metallic nanoparticles. Nanomedicine, 6(2), 257-262(2010).

34. Ingle, A., Gade, A., Pierrat, S., Sonnichsen, C. and Rai, M.K., Mycosynthesis of silver nanoparticles using the fungus Fusarium acuminatum and its activity against some human pathogenic bacteria. Curr. Nanosci. 4, 141-144(2008).

Egypt. J. Chem. 56, No. 1 (2013) 
35. Gade, A.K., Bonde, P., Ingle, A.P., Marcato, P.D., Duran, N. and Rai, M.K., Exploitation of Aspergillus niger for synthesis of silver nanoparticles. J. Biobased Mater. Bioenergy. 2, 243-247 (2008).

36. Mukherjee, P., Roy, M., Mandal, B.P., Dey, G.K., Mukherjee, P.K., Ghatak, J., Tyagi, A.K. and Kale, S.P., Green synthesis of highly stabilized nanocrystalline silver particles by a non-pathogenic and agriculturally important fungus $T$. asperellum. Nanotechnology, 19, 103-110 (2008).

37. Sastry, M., Ahmad, A., Khan, M.I. and Kumar, R., Biosynthesis of metal nanoparticles using fungi and actinomycetes. Curr. Sci. 85(2),162-170 (2003).

38. Bhattacharya, D. and Gupta, R.K., Nanotechnology and potential of microorganisms. Critical Reviews in Biotechnology, 25, 199-204 (2005).

39. Riddin, T.L., Gericke, M. and Whiteley, C.G., Analysis of the inter- and extracellular formation of platinum nanoparticles by Fusarium oxysporum $\mathrm{f} \mathrm{sp}$ lycopersici using response surface methodology. Nanotechnology, 17, 34823489(2006).

40. Duran, N., Alves, O.L., De Souza, G.I.H., Esposito, E. and Marcato, P.D., Antibacterial effect of silver nanoparticles by fungal process on textile fabrics and their effluent treatment. J. Biomed. Nanotechnol. 3, 203-208(2007).

41. Ingle, A., Gade, A., Pierrat, S., Sonnichsen, C. and Rai, M.K., Mycosynthesis of silver nanoparticles using the fungus Fusarium acuminatum and its activity against some human pathogenic bacteria. Curr.Nanosci. 4,141-144(2008).

42. Kumar, V. and Yadav, S.K., Plant-mediated synthesis of silver and gold nanoparticles and their applications. J. Chem. Technol. Biotechnol. 84,151-157 (2009).

43. Thakkar, K.N., Mhatre, S.S. and Parikh, R.Y., Biological synthesis of metallic nanoparticles. Nanomedicine, 6(2), 257-262(2010).

44. El-Rafie, M.H., Mohamed, A.A., Shaheen, Th.I. and Hebeish, A., Bio-synthesis and applications of silver nanoparticles onto cotton fabrics. Carbohydrate Polymers, 90, 915-920 (2012).

45. Bhattacharya, D. and Rajinder, G., Nanotechnology and potential of microorganisms. Critical Reviews in Biotechnology, 25, 199-204 (2005).

46. Sastry, M., Ahmad, A., Khan, M.I. and Kumar, R., Weinheim, Microbial Nanoparticle Production. In: C. M. Niemeyer, \& C. A. Mirkin (Ed.). Germany: Wiley-VCH (2004). 


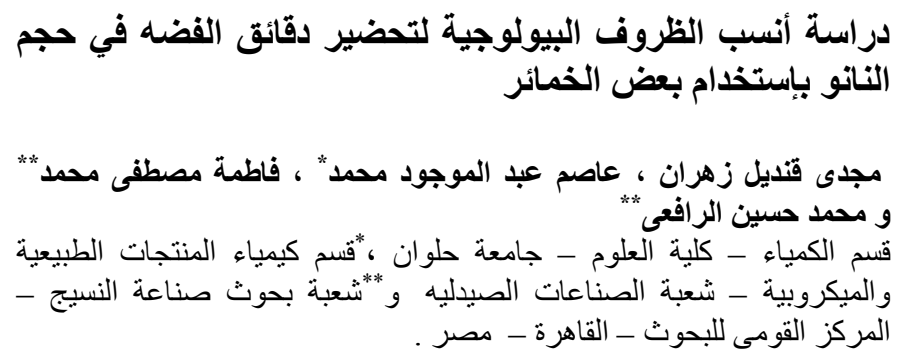

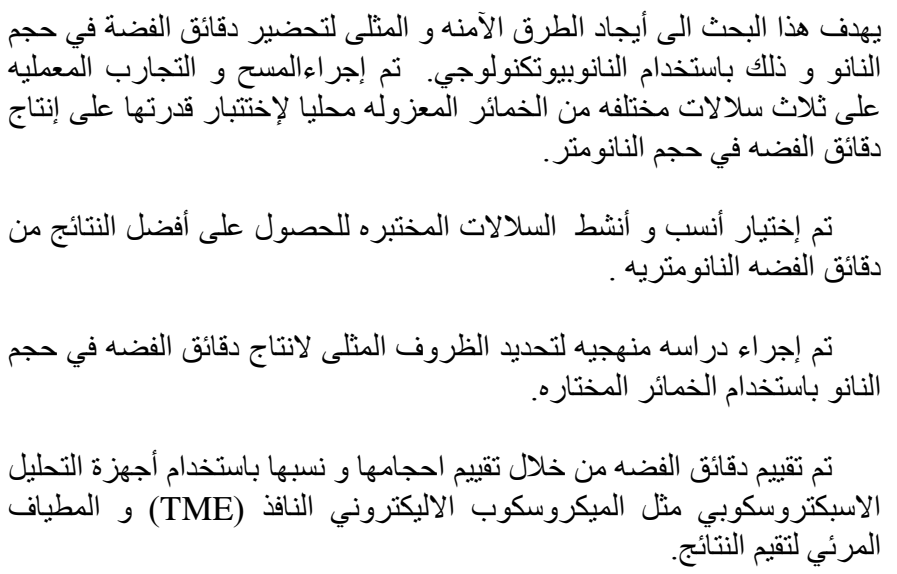

